\title{
A Study on the Correlations between Investor Sentiment and Stock Index and Macro Economy Based on EEMD Method
}

\author{
Yong Fang \\ School of Statistics and Mathematics, Shanghai Finance University, Shanghai, China \\ Email: yongf72@163.com
}

Received 29 July 2015; accepted 27 September 2015; published 30 September 2015

Copyright (C) 2015 by author and Scientific Research Publishing Inc.

This work is licensed under the Creative Commons Attribution International License (CC BY). http://creativecommons.org/licenses/by/4.0/

c) (i) Open Access

\section{Abstract}

This paper tried to utilize Ensemble Empirical Mode Decomposition (EEMD) to explore the correlations between investor sentiment and stock index and macro economy, as well as the prediction capacity of the short-term fluctuation, medium-term fluctuation and long-term trend of investor sentiment in the future stock market return. Firstly, dynamic factor model (DFM) was used to extract sentiment factors from 5 proxy variables of investor sentiment. Then, characteristics comparison and lead-lag relationship analyses were made on the short-term fluctuation, mediumterm fluctuation and long-term trend of investor sentiment index, Shanghai Stock Index and macro index. Finally, whether the original signals of investor sentiment and each component can predict the size and the direction of future market returns was tested. Results indicated that highfrequency sentiment signals had a significant reverse prediction capacity on the short-term and medium-term future market returns. Moreover, low-frequency sentiment signals had a stronger prediction capacity in the direction of future market returns than original sentiment signals, high-frequency sentiment signals and residual signals.

\section{Keywords}

Investor Sentiment, Stock Index, Macro Economy, DFM, EEMD

\section{Introduction}

In the behavioral financial theory, investor sentiment is a core concept as well as a research hotspot in the present academic field and practice field. The so-called investor sentiment refers to the expectation of investors on a specific risk asset or the overall market. Different from the rational expectation theory by traditional econ- 
omists, behavioral financial theory holds the idea that the real expectation of investors usually presents irrational characteristics and systematic bias, which may have great influences on the decision-making of investors and price fluctuation of risk assets and even trigger financial crisis.

Many literatures depict the dynamics of sentiment by constructing theoretical models and analyze the influences of sentiment dynamics on asset price fluctuation. The belief diffusion model established by Kirman (1993, 2005) according to Markov chain and the mutual mimetic contagion model established by Lux (1995) with the aid of differential equation method described the evolution mechanism of herding sentiment. Static noise trading model by De Long, Shleifer, Summers, \& Waldmann (1990a), dynamic noise trading model by Binswanger (1999), static overconfidence and self-attribution model by Daniel, Hirshleifer, \& Subrahmanyam (1998), and dynamic overconfidence and self-attribution model by Gervais \& Odean (2001) described the evolution mechanism of private noise sentiment. Positive feedback model by De Long, Shleifer, Summers, \& Waldmann (1990b) and the behavior model by Westerhoff (2004), which reflected two basic psychological factors, fear and greed, in the market, and portrayed the evolution mechanism of momentum sentiment.

Moreover, many literatures made empirical tests on whether investor sentiment could predict future stock or market returns. De Bondt \& Thaler (1985) sorted all the listed stocks in New York Stock Exchange during 1926 to 1982 according to the accumulated return rate in the past 3 years, and two investment portfolios were constructed according to 35 stocks with the best performance and 35 stocks with the worst performance, which respectively called winner portfolio and loser portfolio. Then, the accumulated return rates of these 2 portfolios in the coming 3 years were investigated. Results found that the loser portfolio presented a high return while the winner portfolio presented a low return. This phenomenon was called winner-loser effect, indicating that momentum factor was an effective investor sentiment measurement which could effectively predict the future return of the investment portfolio. Fisher \& Statman (2000) found that investment portfolio shareholding ratio which represented Wall Street strategist sentiment and Bull Market Sentiment Index (BSI) which represented individual investor sentiment could be used as reversing indicator of S\&P500 index returns. Brown \& Cliff (2004) studied the influences of investor sentiment on the short-term and long-term market return. Results indicated that investor sentiment had no significant influence on the short-term return of the stock market while it had a significantly negative correlation with the future 1 - 3 years' return rate of the stock market. Baker \& Wurgler (2006) found that investor sentiment was a systemic factor that influenced the stock return on the basis of empirical analysis. Schmeling (2009) made an empirical study on the basis of 18 countries' panel data and found that investor sentiment had a good reverse prediction capacity on the future stock return. The study of Chung, Hung, \& Yeh (2012) found that investor sentiment had significant prediction capacity on the stock portfolio return in the economic expansion period while investor sentiment had no significant prediction capacity on the stock portfolio return in the economic recession period. Yong (2013) explored the prediction capacity of investor sentiment on market returns and early-warning ability on market crisis. The results indicated that the higher the investor sentiment was, the smaller future market returns was and the higher the possibility of future negative market returns was. Moreover, overly high market sentiment may increase the risk of crisis occurrence. Huina, Scott, \& Johan (2011) established investor sentiment index by use of new investigation and big data from Twitter and Google, then investigated the influences of these investor sentiment indexes on some principal financial indicators such as Dow Jones index, stock trading volume, VIX and gold price. The results demonstrated that weekly Google financial search data could well predict the stock market changes and investor sentiment index calculated by Twitter data could significantly predict the stock market returns in the coming 1 - 2 days. By aid of the issued articles and comments on Seeking Alpha, the largest investment social network site, and issued news reports and comments on Dow Jones News Service (DJNS), Chen et al. (2014) established the investor sentiment index by using text identification method. The results found that this investor sentiment index could effectively predict future stock return.

In view of signal processing, investor sentiment, as a signal, is formed by overlaid signal sources of various frequencies. This paper utilized Ensemble Empirical Mode Decomposition (EEMD) to decompose investor sentiment signals into several important signal sources of various frequencies, namely, Intrinsic Mode Functions (IMFs). Then, IMFs were reconstructed into short-term fluctuation item (high-frequency signal), medium-term fluctuation item (low-frequency signal) and long-term trend (residual signal). Finally, the correlations between the short-term fluctuation, medium-term fluctuation and long-term trend of investor sentiment and stock index and macro economy as well as their prediction capacity on future stock market returns were investigated. 


\section{Calculation of Sentiment Index}

Firstly, the following 5 variables were selected as the proxy variables of investor sentiment, increment of stock accounts $\left(X_{1}\right)$, turnover rate $\left(X_{2}\right)$, number of IPO companies $\left(X_{3}\right)$, arithmetic mean return rate on the first day of IPO $\left(X_{4}\right)$, arithmetic mean discount rate of closed-end fund $\left(X_{5}\right)$. The monthly data of the above 5 proxy variables during January 1999 to December 2014 were selected, in the total number of 192. Among them, data of $X_{1}, X_{2}, X_{3}$, and $X_{4}$ were from Wind Financial Terminal and data of $X_{5}$ were from CSMAR database. Figure 1 shows the time series of the above 5 proxy variables. Among them, the solid line represented proxy variables and corresponded to the left axle, while the dotted line represented Shanghai Stock Index and corresponded to the right axle. The data of Shanghai Stock Index were from Wind Financial Terminal.

Next, Dynamic Factor Model (DFM) was used to extract sentiment factor from 5 sentiment proxy variables. DFM allows latent factor and random disturbance term to have autoregressive structure, which can well describe the dynamics of economic and financial time series. Details about the introduction and application of DFM please refer to Geweke (1977), Sargent \& Sims (1977), Stock \& Watson (1989), and Watson \& Engle (1983).

The extraction model of dynamic sentiment factor can be expressed as

$$
X_{i t}=\gamma_{i} \text { Sentiment }_{t}+\varepsilon_{i t}, i=1, \cdots, 5 \text {, }
$$

where Sentiment $t_{t}$ is sentiment factor and $\gamma_{i}$ is factor loading. Sentiment factor Sentiment $t_{t}$ owns the following $\operatorname{AR}(p)$ structure

$$
\text { Sentiment }_{t}=\sum_{j=1}^{p} \phi_{j} \text { Sentiment }_{t-j}+w_{t}, w_{t} \sim \text { i.i.d. } N(0,1) \text {. }
$$
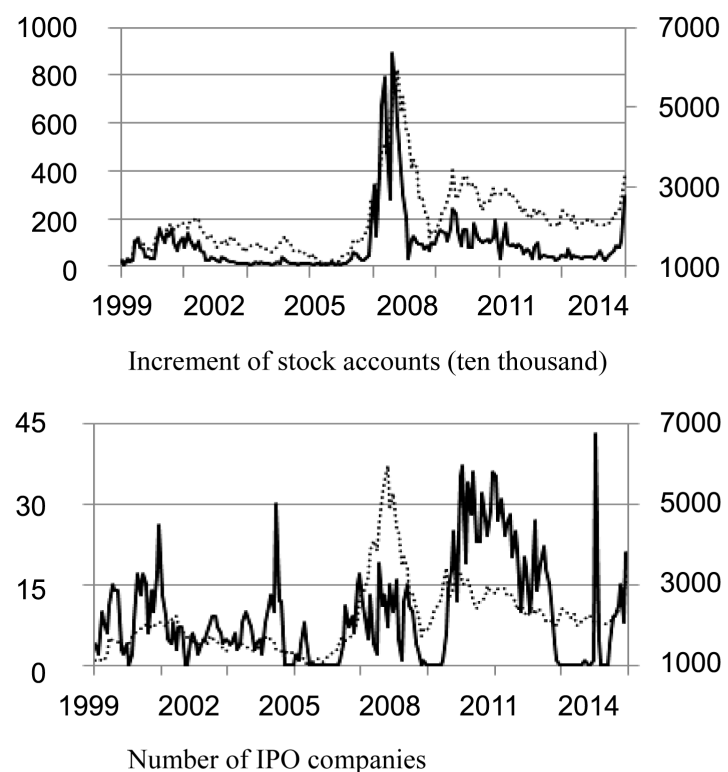
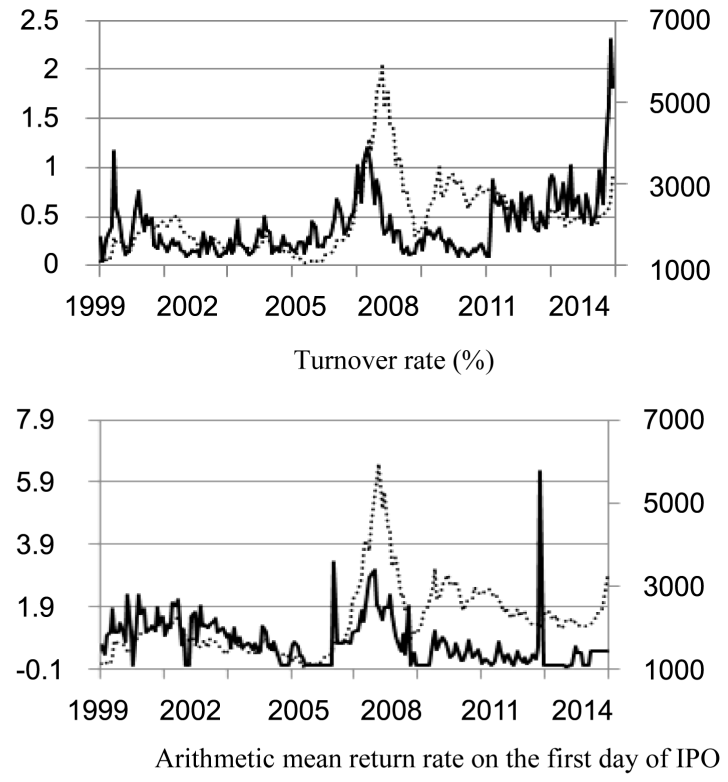
7000 6000 5000 4000 3000 2000 1000

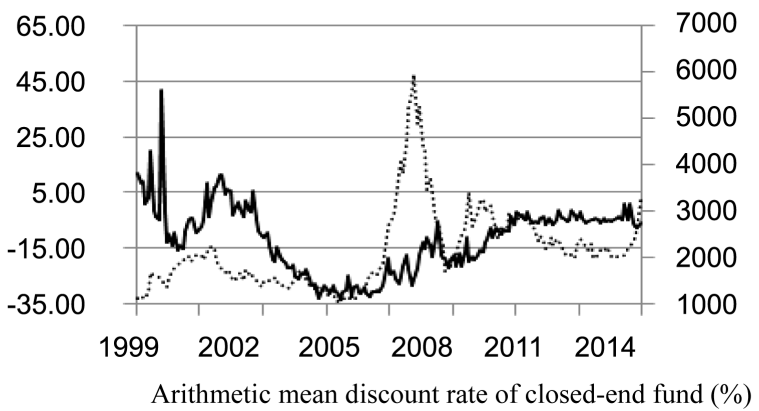

Figure 1. Time series of 5 proxy variables. 
Random disturbance term $\varepsilon_{i t}$ owns the following $\operatorname{AR}(q)$ structure

$$
\varepsilon_{i t}=\sum_{j=1}^{q} \psi_{i j} \varepsilon_{i, t-j}+v_{i t}, v_{i t} \sim N\left(0, \sigma_{i}^{2}\right), E\left(V_{t} V_{t}^{\prime}\right)=\operatorname{diag}\left(\sigma_{1}^{2}, \cdots, \sigma_{5}^{2}\right),
$$

where $V_{t}=\left(v_{1 t}, \cdots, v_{5 t}\right)^{\prime}$.

In view of that IPO suffered several times of suspension in the sampling period, this paper adopted cubic spline interpolation method to fill the missing data of $X_{3}$ and $X_{4}$. Suppose $p=q=1$, the parameter estimation results of DFM is listed in Table $1 .{ }^{* *}$ and ${ }^{* * *}$ respectively represent the significance levels at 0.05 and 0.005 .

Figure 2 shows the time series of investor sentiment index, Shanghai Stock Index and Macro Prosperity Index, which is a proxy variable of macro economy. The data of Macro Prosperity Index were from Wind Financial Terminal.
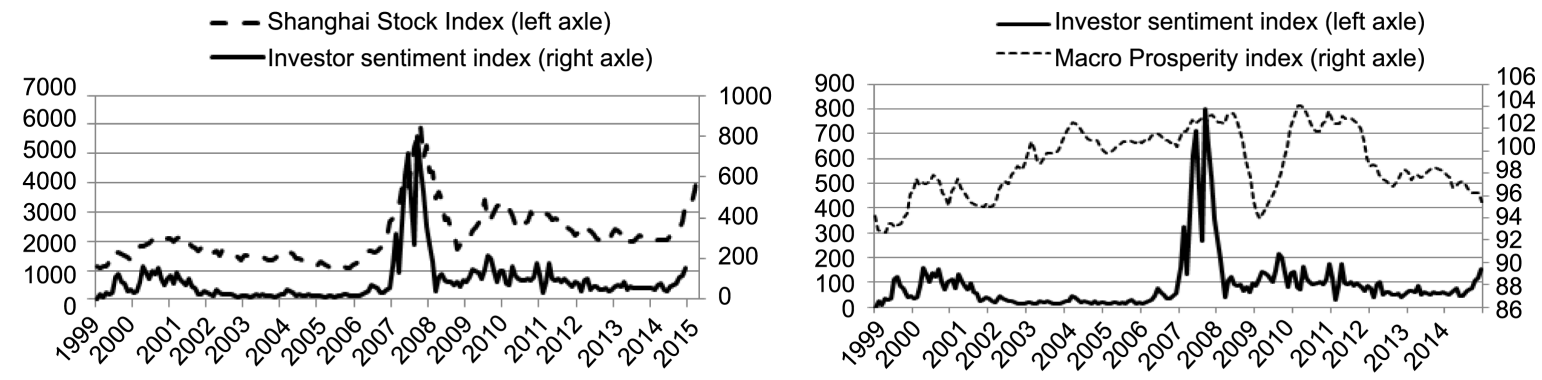

Figure 2. Investor sentiment index, Shanghai Stock Index and Macro Prosperity index.

Table 1. Parameter estimation results of DFM.

\begin{tabular}{|c|c|c|c|c|}
\hline Parameters & Estimation values & OIM standard errors & z statistics & $\mathrm{P}$ values (two tails) \\
\hline$\phi_{1}$ & 0.9921 & 0.0099 & 100.17 & $0.000^{* * * *}$ \\
\hline$\gamma_{1}$ & 27.0395 & 8.4943 & 3.18 & $0.001^{* * *}$ \\
\hline$\psi_{11}$ & 0.8456 & 0.0472 & 17.91 & $0.000^{* * * *}$ \\
\hline$\sigma_{1}^{2}$ & 4268.315 & 572.9831 & 7.45 & $0.000^{* * * *}$ \\
\hline$\gamma_{2}$ & 0.1012 & 0.3028 & 3.34 & $0.001^{* * * *}$ \\
\hline$\psi_{21}$ & 0.4980 & 0.2379 & 2.09 & $0.036^{* *}$ \\
\hline$\sigma_{2}^{2}$ & 0.0203 & 0.0076 & 2.67 & $0.004^{* * * *}$ \\
\hline$\gamma_{3}$ & 1.2002 & 0.4806 & 2.50 & $0.013^{* *}$ \\
\hline$\psi_{31}$ & 0.7897 & 0.0597 & 13.22 & $0.000^{* * * *}$ \\
\hline$\sigma_{3}^{2}$ & 44.7594 & 4.8340 & 9.26 & $0.000^{* * *}$ \\
\hline$\gamma_{4}$ & 0.1330 & 0.0465 & 2.86 & $0.004^{* * *}$ \\
\hline$\psi_{41}$ & 0.8495 & 0.0455 & 18.66 & $0.000^{* * *}$ \\
\hline$\sigma_{4}^{2}$ & 0.3419 & 0.037 & 9.24 & $0.000^{* * *}$ \\
\hline$\gamma_{5}$ & -0.9673 & 0.6143 & -1.57 & 0.115 \\
\hline$\psi_{51}$ & 0.9097 & 0.0316 & 28.75 & $0.000^{* * * *}$ \\
\hline$\sigma_{5}^{2}$ & 36.0956 & 3.8316 & 9.42 & $0.000^{* * * *}$ \\
\hline \multicolumn{2}{|c|}{ Wald Chi2(11) } & & 14440.03 & \\
\hline \multicolumn{2}{|c|}{ Prob > Chi2 } & & $0.0000^{* * *}$ & \\
\hline
\end{tabular}




\section{EEMD-Based Correlations Analysis of Sentiment Index, Shanghai Stock Index and Macro Index}

\subsection{EEMD Decomposition of Sentiment Index, Shanghai Stock Index and Macro Index}

Empirical Mode Decomposition (EMD) was put forward by Huang et al. (1998). This method is a circulative iteration algorithm, which can self-adaptively decompose a series of intrinsic mode functions (IMFs) from time series. However, EMD method has a key defect of mode confusion, namely, different IMFs own similar frequency, which may lead to unclear physical significance of IMF. Specific to this defect, Wu et al. (2009) proposed Ensemble Empirical Mode Decomposition (EEMD). Its fundamental principle was that white noise was added in the original time series to form a new time series. Then, EMD was made on the new time series, obtaining a series of IMFs. The above EMD was repeated for $\mathrm{N}$ times and then the IMFs of $\mathrm{N}$ times were averaged, obtaining final IMFs.

In this paper, EEMD was utilized to decompose investor sentiment index, Shanghai Stock Index and macro index and the standard deviation of white noise was set 0.2 and integration number $\mathrm{N}$ was set 100 . Figure 3 shows the original series of sentiment index, 6 IMFs and residual series. The decomposition results of macro index and Shanghai Stock Index were not listed in the paper.

\subsection{IMF Integration and Reconstruction and Characteristics Comparison}

Referring to the practice of Zhang et al. (2008), this paper made IMF integration and reconstruction on sentiment index, Shanghai Stock Index and macro index. Taking sentiment index as an example, Figure 4 lists the mean of 6
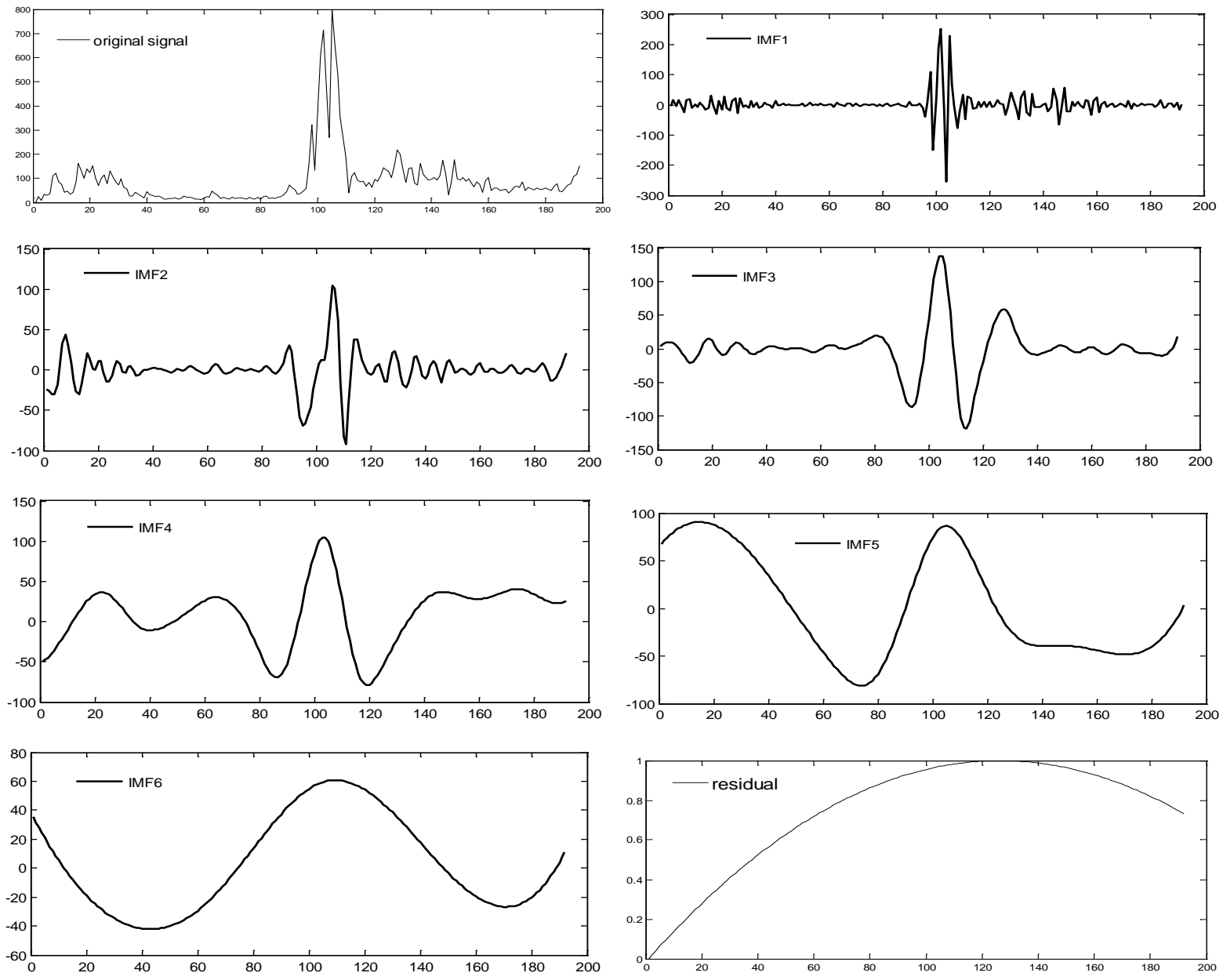

Figure 3. Original series of sentiment index and EEMD results. 


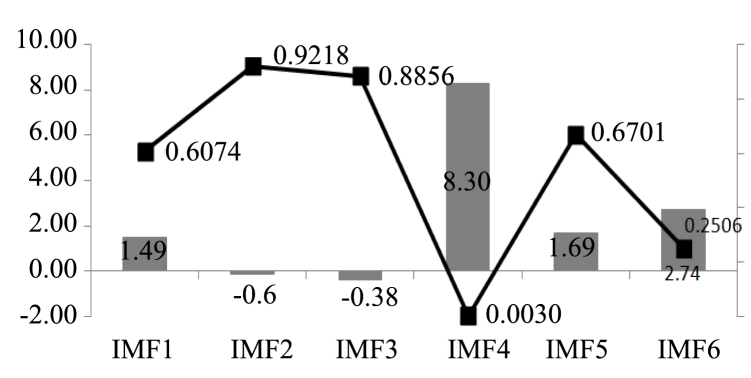

Sentiment index

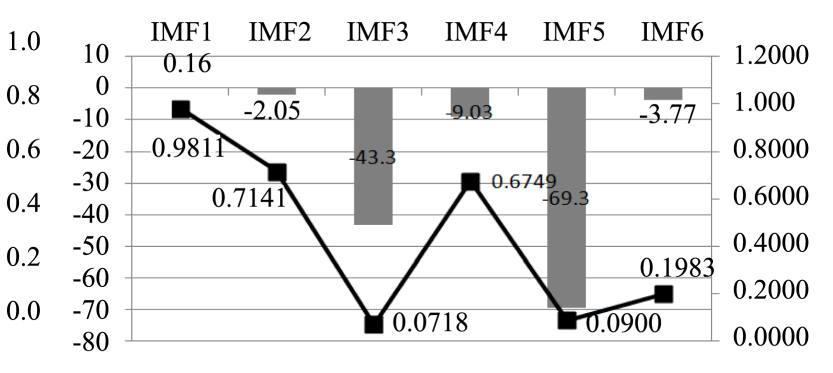

Shanghai Stock Index

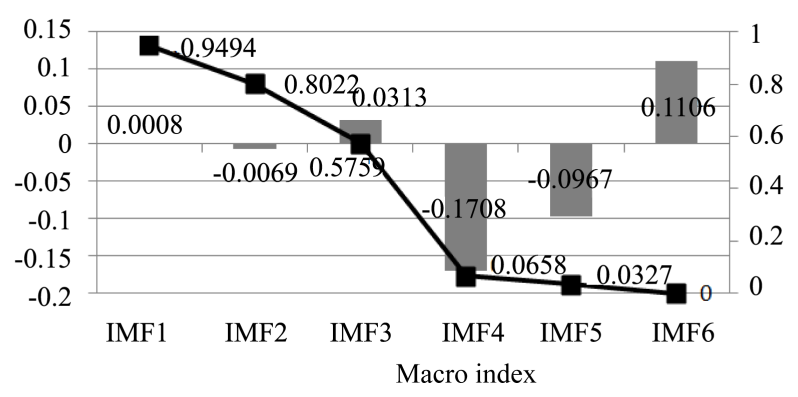

Figure 4. Mean and P value of t-test of IMFs.

IMFs and $\mathrm{P}$ value of t-test on the mean (the mean in the null hypothesis was 0 ). It can be seen that 4th IMF firstly showed the mean of non-0 significantly (with significance level of 0.01). Thus, 1st-3rd IMFs were overlaid as high-frequency signal, representing the short-term fluctuation of investor sentiment; 4th-6th IMFs were overlaid as low-frequency signal, representing the medium-term fluctuation of investor sentiment; residual maintained unchanged, representing long-term trend of investor sentiment. Similarly, mean and P value of t-test of IMFs of Shanghai Stock Index and macro index respectively are also listed in Figure 4 (both 3rd IMF firstly showed the mean of non-0 significantly, with significance level of Shanghai Stock Index of 0.1 and significance level of macro index of 0.05).

Further, from Table 2, it can be seen that in terms of short-term fluctuation, the mean period of investor sentiment was the longest, followed by macro index, and the mean period of Shanghai Stock Index was the shortest. In terms of medium-term fluctuation, the mean periods of investor sentiment and Shanghai Stock Index were equal, both higher than the mean period of macro index. In terms of long-term trend, the mean periods of investor sentiment index, Shanghai Stock Index and macro index were equal. Moreover, the sources of the fluctuation of investor sentiment index, Shanghai Stock Index and macro index presented different modes. In terms of investor sentiment index, the variance of medium-term fluctuation accounted the highest and was the main source of fluctuation of investor sentiment index, followed by short-term fluctuation, and the variance of long-term trend accounted the lowest. In terms of Shanghai Stock Index, the variance of medium-term fluctuation accounted the highest and was the main source of fluctuation of Shanghai Stock Index, followed by long-term trend, and the variance of short-term fluctuation accounted the lowest, only $1.64 \%$. In terms of macro index, the variance of long-term trend accounted the highest, followed by medium-term fluctuation and the variance of short-term fluctuation accounted the lowest.

\subsection{Correlations Analysis of Sentiment Index, Shanghai Stock Index and Macro Index}

Granger Causality Tests were respectively made on the short-term fluctuations, medium-term fluctuations and long-term trend of three indexes. The optimal lag order of Granger Causality Test was comprehensively judged by likelihood, AIC and BC of VAR model. From Table 3, it can be seen from the high-frequency signal that at the significance level of 0.01 investor sentiment index and Shanghai Stock Index were mutually Granger causality. At the significance level of 0.01, investor sentiment was the Granger cause of macro index, which indicated that in the short-term fluctuation investor sentiment was ahead of macro index. From the low-frequency signal it can be seen that at the significance level of 0.01 investor sentiment index and Shanghai Stock Index were mutually Granger causality; at the significance level of 0.01 investor sentiment index and Shanghai Stock Index 
Table 2. The comparison of mean period and proportion of variance.

\begin{tabular}{ccccccc}
\hline & \multicolumn{2}{c}{ Sentiment index } & \multicolumn{2}{c}{ Shanghai Stock Index } & \multicolumn{2}{c}{ Macro index } \\
Reconstructed series & Mean period & $\begin{array}{c}\text { Proportion of } \\
\text { variance }\end{array}$ & Mean period & $\begin{array}{c}\text { Proportion of } \\
\text { variance }\end{array}$ & Mean period & $\begin{array}{c}\text { Proportion of } \\
\text { variance }\end{array}$ \\
\hline $\begin{array}{c}\text { High frequency } \\
\text { signal }\end{array}$ & 24 & $38.66 \%$ & 9 & $1.64 \%$ & 17 & $17.83 \%$ \\
$\begin{array}{c}\text { Low frequency } \\
\text { signal }\end{array}$ & 96 & $48.75 \%$ & 96 & $59.68 \%$ & 48 & $36.55 \%$ \\
Residual signal & 192 & $12.59 \%$ & 192 & $38.68 \%$ & 192 & $45.62 \%$ \\
\hline
\end{tabular}

Table 3. The results of Granger causality test.

\begin{tabular}{|c|c|c|c|}
\hline Optimal lag order and null hypothesis & High frequency signal & $\begin{array}{c}\text { Low frequency } \\
\text { signal }\end{array}$ & Residual \\
\hline Optimal lag order & 6 & 6 & 1 \\
\hline Sentiment index does not granger cause Shanghai Stock Index & $0.0000^{* * *}$ & $0.0000^{* * *}$ & $0.0000^{* * *}$ \\
\hline Shanghai Stock Index does not granger cause sentiment index & $0.0000^{* * *}$ & $0.0000^{* * *}$ & $0.0000^{* * *}$ \\
\hline Sentiment index dose not granger cause macro index & $0.0983^{*}$ & $0.0009^{* * *}$ & $0.0000^{* * *}$ \\
\hline Macro index does not granger cause sentiment index & 0.3401 & 0.3281 & $0.0000^{* * *}$ \\
\hline Shanghai Stock Index does not granger cause macro index & 0.4943 & $0.0039^{* * *}$ & $0.0000^{* * *}$ \\
\hline Macro index does not granger cause Shanghai Stock Index & 0.2064 & 0.2086 & $0.0000^{* * *}$ \\
\hline
\end{tabular}

were the Granger cause of macro index, which indicated that in the medium-term fluctuation investor sentiment and Shanghai Stock Index were ahead of macro index. From the residual signal it can be seen that at the significance level of 0.01 investor sentiment index, Shanghai Stock Index and macro index were mutually Granger causality.

\section{Prediction Capability Test of Sentiment Component at Different Scales on Future Market Returns}

Whether the original signal and each component of investor sentiment can predict future market returns was tested. The logarithmic return rate of Shanghai Stock Index with holding period of 1, 2, 3, 6, 9 and 12 months, $R_{t}^{k}$, can be expressed as

$$
R_{t}^{k}=\ln P_{t+k-1}-\ln P_{t-1},
$$

where $P_{t}$ is the price of Shanghai Stock Index.

In consideration of that return series $R_{t}^{k}$ owns significant autocorrelation and fluctuation aggregating feature, GARCH model was adopted to test the prediction capacity and each component of investor sentiment on future market returns and conditional variance.

The mean equation of GARCH(1,1) model can be expressed as

$$
R_{t}^{k}=a^{k} R_{t-1}^{k}+b^{k} \text { Sentiment }_{t-1}+u_{t}^{k},
$$

where Sentiment $t_{t-1}$ is investor sentiment and each component and $u_{t}^{k}$ is random disturbance term.

The volatility equation can be expressed as

$$
\sigma_{t}^{k 2}=\alpha^{k}+\beta^{k} u_{t-1}^{k 2}+\delta^{k} \text { Sentiment }{ }_{t-1}
$$

where $\sigma_{t}^{k 2}$ is the conditional variance of random disturbance term $u_{t}^{k}$.

Table 4 lists the parameter estimation results of $\operatorname{GARCH}(1,1)$ method at each holding period. It can be seen that high-frequency sentiment signal owned significant reverse prediction capability on short-term and medium-term future market returns (1, 2, 3 and 6 months). Original sentiment signal, low-frequency sentiment signal and residual signal had no significant prediction capability on future market returns at each holding period. 
Table 4. The results of GARCH model.

\begin{tabular}{|c|c|c|c|c|c|c|c|}
\hline Holding & & $k=1$ & $k=2$ & $k=3$ & $k=6$ & $k=9$ & $k=12$ \\
\hline \multirow{2}{*}{$\begin{array}{l}\text { Original } \\
\text { signal }\end{array}$} & $b^{k}$ & $\begin{array}{c}0.000034 \\
(0.5250)\end{array}$ & $\begin{array}{c}-0.000003 \\
(0.9592)\end{array}$ & $\begin{array}{c}-0.000047 \\
(0.4786)\end{array}$ & $\begin{array}{c}0.000009 \\
(0.9149)\end{array}$ & $\begin{array}{c}0.000053 \\
(0.5656)\end{array}$ & $\begin{array}{c}0.000043 \\
(0.5725)\end{array}$ \\
\hline & $\delta^{k}$ & $\begin{array}{c}0.000004 \\
(0.2489)\end{array}$ & $\begin{array}{c}0.000006 \\
(0.1732)\end{array}$ & $\begin{array}{c}0.000004 \\
(0.4242)\end{array}$ & $\begin{array}{c}0.000009 \\
(0.3178)\end{array}$ & $\begin{array}{c}0.000008 \\
(0.1797)\end{array}$ & $\begin{array}{c}0.000006 \\
(0.3173)\end{array}$ \\
\hline \multirow{2}{*}{$\begin{array}{l}\text { High } \\
\text { frequency } \\
\text { signal }\end{array}$} & $b^{k}$ & $\begin{array}{c}-0.000111 \\
\left(0.0661^{*}\right)\end{array}$ & $\begin{array}{l}-0.000226 \\
\left(0.0164^{* *}\right)\end{array}$ & $\begin{array}{l}-0.000553 \\
\left(0.0000^{* * * *}\right)\end{array}$ & $\begin{array}{c}-0.000252 \\
\left(0.0280^{* *}\right)\end{array}$ & $\begin{array}{c}-0.000042 \\
(0.7185)\end{array}$ & $\begin{array}{c}-0.000059 \\
(0.5426)\end{array}$ \\
\hline & $\delta^{k}$ & $\begin{array}{c}-0.000003 \\
(0.5481)\end{array}$ & $\begin{array}{c}-0.000004 \\
(0.4267)\end{array}$ & $\begin{array}{c}0.000004 \\
(0.5043)\end{array}$ & $\begin{array}{c}0.000001 \\
(0.8791)\end{array}$ & $\begin{array}{c}-0.000004 \\
(0.3375)\end{array}$ & $\begin{array}{c}0.000006 \\
(0.4116)\end{array}$ \\
\hline \multirow{2}{*}{$\begin{array}{l}\text { Low } \\
\text { frequency } \\
\text { signal }\end{array}$} & $b^{k}$ & $\begin{array}{c}0.000096 \\
(0.1886)\end{array}$ & $\begin{array}{c}0.000058 \\
(0.5320)\end{array}$ & $\begin{array}{c}0.000059 \\
(0.5389)\end{array}$ & $\begin{array}{c}-0.000020 \\
(0.8638)\end{array}$ & $\begin{array}{c}-0.000097 \\
(0.4203)\end{array}$ & $\begin{array}{c}-0.000026 \\
(0.8676)\end{array}$ \\
\hline & $\delta^{k}$ & $\begin{array}{c}0.000004 \\
(0.1978)\end{array}$ & $\begin{array}{c}0.000006 \\
(0.2288)\end{array}$ & $\begin{array}{c}0.000004 \\
(0.3345)\end{array}$ & $\begin{array}{c}0.000008 \\
(0.2070)\end{array}$ & $\begin{array}{l}0.000007 \\
\left(0.0763^{*}\right)\end{array}$ & $\begin{array}{c}0.000005 \\
(0.3099)\end{array}$ \\
\hline \multirow{2}{*}{ Residual signal } & $b^{k}$ & $\begin{array}{c}-0.000007 \\
(0.9109)\end{array}$ & $\begin{array}{c}0.000011 \\
(0.8880)\end{array}$ & $\begin{array}{c}0.000016 \\
(0.8430)\end{array}$ & $\begin{array}{c}0.000028 \\
(0.7719)\end{array}$ & $\begin{array}{c}0.000043 \\
(0.6342)\end{array}$ & $\begin{array}{c}0.000042 \\
(0.6648)\end{array}$ \\
\hline & $\delta^{k}$ & $\begin{array}{c}0.000003 \\
(0.3554)\end{array}$ & $\begin{array}{l}0.000005 \\
\left(0.0726^{*}\right)\end{array}$ & $\begin{array}{c}0.000006 \\
(0.3532)\end{array}$ & $\begin{array}{c}0.000005 \\
(0.3110)\end{array}$ & $\begin{array}{c}0.000004 \\
(0.3183)\end{array}$ & $\begin{array}{c}0.000004 \\
(0.5084)\end{array}$ \\
\hline
\end{tabular}

Each sentiment component had no significant prediction capability on the conditional variance of market returns at each holding period.

Moreover, Logit regression model was utilized to test whether each sentient component can predict the direction of future market returns (positive or negative).

The indicator variable of the direction of future market returns is established as

$$
d_{t}^{k}=\left\{\begin{array}{ll}
1 & R_{t}^{k}>0 \\
0 & R_{t}^{k}<0
\end{array} .\right.
$$

Logit regression model can be expressed as

$$
\operatorname{Pr}\left\{d_{t}^{k}=1\right\}=f\left(\mu^{k} \text { Sentiment }_{t-1}\right),
$$

where $f(x)=\mathrm{e}^{x} /\left(1+\mathrm{e}^{x}\right)$.

Table 5 lists the parameter estimation results of Logit regression model at each holding period. It can be seen that original sentiment signals had a significantly positive prediction capability on the direction of medium-term and long-term future market returns (6, 9 and 12 months), namely, the higher the sentiment was, the greater the possibility of positive future market return was. High-frequency sentiment signals had a significantly positive prediction capability on the direction of medium-term future market returns (6 and 9 months). Low-frequency sentiment signals had a significantly positive prediction capability on the direction of future market returns (3, 6, 9 , and 12 months). Residual signals had a significantly negative prediction capability on the direction of longterm future market returns ( 9 and 12 months). In comprehensive view, the prediction capability of low-frequency sentiment signals on the direction of future market returns was stronger than those of original sentiment signals.

\section{Concluding Remarks}

This paper utilized EEMD method to respectively decompose investor sentiment, stock index and macro economy index into several important signal sources of various frequencies, such as high-frequency signal representing short-term fluctuation, low-frequency signal representing medium-term fluctuation and residual signal representing long-term trend. On the basis of EEMD results, the correlations among investor sentiment, stock index and macro economy as well as their prediction capacity on future stock market returns were investigated.

Investor sentiment is one of the core concepts in behavioral finance theory and it is characterized by irrationality and systematic bias, which may greatly affect the fluctuation of asset prices. This paper adopted signal 
Table 5. The results of Logit model.

\begin{tabular}{|c|c|c|c|c|c|c|c|}
\hline & Holding period & $k=1$ & $k=2$ & $k=3$ & $k=6$ & $k=9$ & $k=12$ \\
\hline \multirow{4}{*}{$\mu_{k}$} & Original signal & $\begin{array}{c}0.001553 \\
(0.1451)\end{array}$ & $\begin{array}{c}0.000230 \\
(0.8156)\end{array}$ & $\begin{array}{c}0.000647 \\
(0.5173)\end{array}$ & $\begin{array}{c}0.003194 \\
\left(0.0123^{* * *}\right)\end{array}$ & $\begin{array}{c}0.003370 \\
\left(0.0100^{* *}\right)\end{array}$ & $\begin{array}{c}0.003185 \\
\left(0.0132^{* * *}\right)\end{array}$ \\
\hline & $\begin{array}{l}\text { High } \\
\text { frequency signal }\end{array}$ & $\begin{array}{c}-0.000839 \\
(0.6925)\end{array}$ & $\begin{array}{c}-0.001623 \\
(0.4534)\end{array}$ & $\begin{array}{c}-0.000194 \\
(0.9266)\end{array}$ & $\begin{array}{l}0.005685 \\
\left(0.0349^{* *}\right)\end{array}$ & $\begin{array}{l}0.004602 \\
\left(0.0692^{*}\right)\end{array}$ & $\begin{array}{c}0.003408 \\
(0.1491)\end{array}$ \\
\hline & $\begin{array}{c}\text { Low } \\
\text { frequency signal }\end{array}$ & $\begin{array}{c}0.003081 \\
(0.1077)\end{array}$ & $\begin{array}{l}0.001977 \\
(0.2930)\end{array}$ & $\begin{array}{l}0.004163 \\
\left(0.0348^{* *}\right)\end{array}$ & $\begin{array}{c}0.008101 \\
\left(0.0004^{* * * *}\right)\end{array}$ & $\begin{array}{c}0.014627 \\
\left(0.0000^{* * * *}\right)\end{array}$ & $\begin{array}{c}0.017103 \\
\left(0.0000^{* * * *}\right)\end{array}$ \\
\hline & Residual signal & $\begin{array}{c}0.002314 \\
(0.1668)\end{array}$ & $\begin{array}{c}0.000056 \\
(0.9733)\end{array}$ & $\begin{array}{c}-0.001298 \\
(0.4360)\end{array}$ & $\begin{array}{c}-0.001105 \\
(0.5072)\end{array}$ & $\begin{array}{c}-0.003049 \\
\left(0.0703^{*}\right)\end{array}$ & $\begin{array}{c}-0.003316 \\
\left(0.0495^{* *}\right)\end{array}$ \\
\hline
\end{tabular}

processing method to study investor sentiment and obtained some interesting results, providing us a new research perspective.

\section{Acknowledgements}

This paper is supported by the National Natural Science Foundation of China through Grant NO. 71171133.

\section{References}

Baker, M., \& Wurgler, J. (2006). Investor Sentiment and Cross-Section of Stock Returns. Journal of Finance, 61, 1645-1680.

Binswanger, M. (1999). Stock Markets, Speculative Bubbles and Economic Growth: New Dimensions in the Co-Evolution of Real and Financial Market. Edward Elgar Publishing Limited.

Brown, G. W., \& Cliff, M. T. (2004). Investor Sentiment and the Near-Term Stock Market. Journal of Empirical Finance, $11,1-27$

Chen, H. L., Prabuddha, D., Yu, J. H., \& Byoung-Hyoun, H. (2014). Wisdom of Crowds: The Value of Stock Opinions Transmitted through Social Media. Review of Financial Studies, 27, 1367-1403.

Chung, S. L., Hung, C. H., \& Yeh, C. Y. (2012). When Does Investor Sentiment Predict Stock Returns? Journal of Empirical Finance, 19, 217-240.

Daniel, K., Hirshleifer, D., \& Subrahmanyam, A. (1998). Investor Psychology and Investor Security Market under- and Overreactions. Journal of Finance, 53, 1839-1886.

De Bondt, W. F. M., \& Thaler, R. H. (1985). Dose the Stock Market Overreact? Journal of Finance, 40, 793-805.

De Long, J. B., Shleifer, A., Summers, L. H., \& Waldmann, R. J. (1990a). Noise Trader Risk in Financial Markets. The Journal of Political Economy, 98, 703-738.

De Long, J. B., Shleifer, A., Summers, L. H., \& Waldmann, R. J. (1990b). Positive Feedback Investment Strategies and Destabilizing Rational Speculation. Journal of Finance, 45, 375-395.

Fisher, K. L., \& Statman, M. (2000). Investor Sentiment and Stock Returns. Financial Analysts Journal, 56, 16-23.

Gervais, S., \& Odean, T. (2001). Learning to Be Overconfident. The Review of Financial Studies, 14, 1-27.

Geweke, J. (1977). The Dynamic Factor Analysis of Economic Time Series Models. Amsterdam: North-Holland.

Huang, N. E., Shen, Z., \& Long, S. R. et al. (1998). The Empirical Mode Decomposition and the Hilbert Spectrum for Nonlinear and Non-stationary Time Series Analysis. Proceedings of the Royal Society A, Mathematical, Physical and Engineering Sciences, 454, 903-995.

Huina, M., Scott, C., \& Johan, B. (2011). Predicting Financial Markets: Comparing Survey, News, Twitter and Search Engine Data. General Information.

Kirman, A. (1993). Ants, Rationality and Recruitment. The Quarterly Journal of Economics, 108, 137-156.

Kirman, A., \& Teyssiere, G. (2005). Testing for Bubbles and Change-points. Journal of Economic Dynamics and Control, 29, 765-799.

Lux, T. (1995). Herd Behavior, Bubbles and Crashes. The Economic Journal, 105, 881-896.

Sargent, T. J., \& Sims, C. A. (1977). Business Cycle Modeling without Pretending to Have Too Much a Priori Economic Theory. Minneapolis: Federal Reserve Bank of Minneapolis.

Schmeling, M. (2009). Investor Sentiment and Stock Returns: Some International Evidence. Journal of Empirical Finance, 
16, 394-408.

Stock, J. H., \& Watson, M. W. (1989). New Indexes of Coincident and Leading Economic Indicators. Cambridge, MA: MIT Press.

Watson, M. W., \& Engle, R. F. (1983). Alternative Algorithms for the Estimation of Dynamic Factor, MIMIC and Varying Coefficient Regression Models. Journal of Econometrics, 23, 385-400.

Westerhoff, F. H. (2004). Greed, Fear and Stock Market Dynamics. Physica A, 343, 635-642.

Wu, Z. H., \& Huang, N. E. (2009). Ensemble Empirical Mode Decomposition: A Noise-assisted Data Analysis Method. Advances in Adaptive Data Analysis, 1, 1-41.

Yong, F. (2013). Investor Sentiment Dynamics and Phase Transition of Stock Market. Journal of Management Science and Statistical Decision, 10, 70-85.

Zhang, X., Lai, K. K., \& Wang, S. Y. (2008). A New Approach for Crude Oil Price Analysis Based on Empirical Mode Decomposition. Energy Economics, 30, 905-918. 